\title{
A SCI Analysis Model: Research on Influencing Factors of Local E-Government Responsiveness in China
}

\author{
Shaoqing Tian $\mathbb{D}^{1,2}$ Rongrong He $\mathbb{D}^{1,},{ }^{2,3}$ Chongli Huang, ${ }^{2}$ Qiong Feng, ${ }^{2}$ and Fan Jiang ${ }^{2}$ \\ ${ }^{1}$ Postdoctoral Station of Business Administration, Harbin University of Commerce, Harbin 150028, China \\ ${ }^{2}$ College of Applied Science and Technology, Hainan University, Haikou 570228, China \\ ${ }^{3}$ College of Public Administration, Sichuan University, Chengdu 610065, China \\ Correspondence should be addressed to Rongrong He; 346762962@qq.com
}

Received 18 December 2020; Revised 8 February 2021; Accepted 20 March 2021; Published 31 March 2021

Academic Editor: Lijun Pei

Copyright (c) 2021 Shaoqing Tian et al. This is an open access article distributed under the Creative Commons Attribution License, which permits unrestricted use, distribution, and reproduction in any medium, provided the original work is properly cited.

In order to explore the influencing factors of the e-government responsiveness in China, the System-Competition-Interaction analysis model was proposed to reflect the ability of e-government to respond to citizens' demands. 960 pieces of information were collected from 480 local e-government websites in China, and field experiments were conducted on how local governments responded to citizens' demands. The results show that there are regional differences in e-government responsiveness in China. The response probability of Northeast China is the lowest, and that of western region is the slowest. The response system and neighborhood effect are the core elements that affect e-government responsiveness. The interaction demands of citizens can not significantly affect government responsiveness. According to the research results, the practical enlightenment is that the future should change from "system-driven response" and "competition-driven response" to "citizen-driven response," which is of a certain practical significance for improving the response level of e-government of local governments in China.

\section{Introduction}

It is the active response of the public sector and the administrative personnel as the respondent to the citizens' demands as the respondent. With the advancement of Internet technology and the popularization of the Internet, various services provided by local government e-government platforms are becoming more and more important to citizens [1]. According to the timing of responses, e-government responses can be divided into fire-extinguishing responses and normalized responses. Normalized responses, compared with the fire-extinguishing responses after the event, are of great significance to improving public satisfaction and maintaining social stability.

The e-government responsiveness (E-GR) is usually affected by multiple complex factors. Therefore, if you want to improve E-GR, you need to analyze the factors that affect government response. Existing research results show that E-GR is affected by multiple factors such as the government itself, the characteristics of citizens, the issues of appeal, and the external environment. Firstly, the response subject is an important factor influencing the response level. The institutionalized political parties and value orientation, the degree of transparency and decentralization of the government, the resources and capabilities of the government itself, the result-oriented management reform, and the subjective attitude of the administrative staff will have a certain impact on the government response [2-5]. Secondly, as the main body of appeal and the response object of the government, citizens' own gender, race, and other attributes, political participation ability, and influence will also have a greater impact on the government response [2-6]. Finally, the external environment in which the government interacts with citizens is also a key factor affecting the government's response, such as the pressure from the superior government, the competition among peers, the level of regional informatization, and public opinion supervision [3, 7-10].

However, the existing research still has certain weaknesses and room for improvement. (1) The research based on case database mainly focuses on the fire-fighting response 
after the event, such as public opinion involving officials or network anticorruption, while the research on normalized response is relatively weak. (2) In recent years, big data research based on the local leaders' message board of the people's network or the leaders' mailbox records in the government portal website has gradually risen in recent years. (3) Big data research based on political-civilian interaction information such as local leaders' message boards on People's Daily Online or leaders' mailbox records on government portals has gradually emerged in recent years. However, due to the complexity of its information generation, the open selectivity, and the lack of some information elements, the research may have endogenous problems and draw false conclusions. (4) In one of the few field experiments, it was designed to ask for information from the government in the name of the research group. In this interactive scene, the appeal comes from "researchers" rather than "real citizens." Therefore, the response results may not reflect the most authentic local response. (5) The existing studies are either aimed at prefecture-level cities or county-level governments, and there is a lack of comparative research on the influencing factors of the two levels of government.

In view of this, this paper aims to conduct an empirical study on the influencing factors of the response level of local governments at prefecture and county levels in China. An analysis framework of System-Competition-Interaction (SCI) was constructed on the basis of literature review, as shown in Figure 1. Based on the field experiment of e-government response level evaluation method, 960 firsthand data of government response were collected to simulated citizens' demands. The response level was also coded in terms of government response, response speed and response quality. Then, the theoretical framework is tested through statistical analysis. Finally, based on the empirical results, the corresponding countermeasures and suggestions are put forward.

\section{Model Construction and Research Hypothesis}

2.1. Model Building. The dependent variable of this study is E-GR. The experimental data was coded immediately after the online experiment by two members of the team. The inconsistency of the code should be discussed and determined by the team. The following model is formed for the main measurement indicators of E-GR.

2.1.1. Responsiveness Probability $\left(R_{P}\right), R_{P}$ is a dummy variable. Through referring to the working cycle of civil servants, the value of $R_{P}$ can be described as follows:

$$
R_{P}= \begin{cases}1, & \text { reply within } 30 \text { working days, } \\ 0, & \text { otherwise. }\end{cases}
$$

2.1.2. Responsiveness Speed $\left(R_{S}\right) . R_{S}$ is a continuous variable. It is determined by the number of days required for

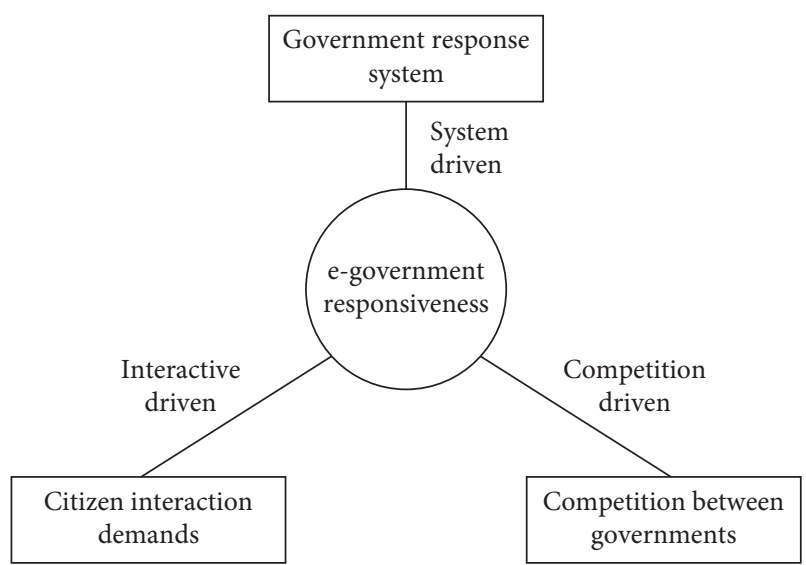

Figure 1: Framework of SCI analysis model.

e-government to respond. This day is called $d$, and the range is $1-30$. For example, $d$ is recorded as 30 when the government responds on the same day, $d$ is recorded as 29 when the government responds the next day, and so on. $d$ is recorded as 0 when the government responds more than 30 working days. Let the constant $a_{s}$ be the $R_{S}$ coefficient, and then the $R_{S}$ can be described as follows:

$$
R_{S}= \begin{cases}a_{s}(31-d), & 1 \leq d \leq 30 \\ 0, & d>30\end{cases}
$$

2.1.3. Responsiveness Quality $\left(R_{Q}\right) . R_{Q}$ is a discrete variable, which is mainly used to measure the consistency of the answer to questions. There are two kinds of problems in citizen's appeal, consultation on house purchase $\left(p_{1}\right)$ and suggestions on city image $\left(p_{2}\right)$.

The $p_{1}$ contains three subquestions $\left(\right.$ Question $\left._{i}\right)$. The Question ${ }_{i}$ is quantified as follows: if the appeal is rejected, it will be recorded as 1; if the appeal is not answered directly, but the corresponding consultation channel is provided, it will be recorded as 2; if the appeal is not answered in time, it will be recorded as 3; if some of the subquestions are answered, it will be recorded as 4; if all the subquestions are answered, it will be recorded as 5; if the questions are answered and their entirety as well as additional information is provided, it will be recorded as 6 as shown in Table 1 .

$p_{2}$ is to measure the quality of the government's response through the indicator of "the degree of adoption of suggestions." $p_{2}$ was quantified as follows: if the appeal is rejected, it will be recorded as 1 ; if people are only prompted to receive a message or to express thanks, it will be recorded as 2; if information in the area of advice is provided in addition to thanks, it will be recorded as 3 ; if it means that the proposal will be submitted to the relevant department or leaders for reference, it will be recorded as 4; if it is clearly indicated that they will attach importance to or adopt the suggestions put forward by citizens, it will be recorded as 5 ; if the proposal is adopted and translated into government action, it will be recorded as 6 as shown in Table 2 .

Let the constant $a_{q}$ be the $R_{Q}$ coefficient; then $R_{Q}$ can be described as follows: 
TABLE 1: Value of response to appeal $1\left(p_{1}\right)$.

\begin{tabular}{lccccccc}
\hline Appeal 1 & Subquestions & Bad & Qualified & Average & Good & Great & Nice \\
\hline \multirow{2}{*}{$p_{1}$} & Question $_{1}$ & 1 & 2 & 3 & 4 & 5 \\
& Question $_{2}$ & 1 & 2 & 3 & 4 & 5 & 6 \\
\hline
\end{tabular}

TABLE 2: Value of response to appeal $2\left(p_{2}\right)$.

\begin{tabular}{lcccccc}
\hline Appeal 2 & Bad & Qualified & Average & Good & Great & Nice \\
\hline$p_{2}$ & 1 & 2 & 3 & 4 & 5 & 6 \\
\hline
\end{tabular}

$$
\begin{aligned}
& p_{1}=\frac{1}{3} \sum_{i=1}^{3} \text { Question }_{i} \\
& R_{Q}=a_{q}\left(p_{1}+p_{2}\right)
\end{aligned}
$$

2.1.4. E-GR ( $\left.R_{E-\text { government }}\right)$. According to the three variables of $R_{P}, R_{S}$, and $R_{Q}, R_{E-\text { government }}$ can be described as follows:

$$
\begin{aligned}
& R_{\text {E-government }}=R_{P}\left(R_{S}+R_{Q}\right), \\
& R_{\text {E-government }}= \begin{cases}a_{s}(31-d)+a_{q}\left(p_{1}+p_{2}\right), & \text { reply within in } 30 \text { working days, } \\
0, & \text { otherwise. }\end{cases}
\end{aligned}
$$

\subsection{Research Hypothesis}

\subsubsection{Hypothesis (H1): The Government Response System has} a Positive Impact on E-GR. The construction of government response system is conducive to improving the government responsiveness. Compared with the "soft constraints" of informal rules such as culture and ideology, the rigid government response system is a "hard constraint" with mandatory and punitive nature. In recent years, some local governments in China have introduced the handling system for citizens to leave messages on network platforms such as "governor's mailbox" and "mayor's mailbox." As shown in Table 3, after sorting out the text of the response system, it is found that the existing system has made relatively clear provisions on the acceptance scope, response time limit, handling quality, and responsibility subject of response. Some local governments have also introduced corresponding supervision and inspection mechanisms to incorporate the government response performance into the government assessment. These measures can increase the external pressure of government response to a certain extent.

The existing research also found that the system and policy issued by the government really played a key role in the interaction between the government and the people. However, there are no clear objectives or assessment indicators in the policy, which make it difficult to play its guiding role [11-13]. The realization of government response also depends on the current institutional environment. At the same time, the corresponding reward and punishment mechanism of the government can influence the decisionmaking of individuals or organizations [14-16], so a good system can ensure the governmental E-GR. On the other hand, the construction of Chinese government response system is a top-down mandatory institutional change. The intervention of the superior government plays a key role [17]. The combination of "authority of superior government" and "rigid response system" can generate great power. In China's political system, the higher-level government has absolute leadership authority over the lower-level government, holds the precious resources for the development of the lower-level government, and controls the career promotion of the lower-level officials [3]. Therefore, the lowerlevel government has a strong motivation to cater to the higher-level government. Especially when the power of local government is centralized, its powerful influence will directly affect the subordinate departments [18]. Moreover, the attitude or instruction of the higher-level government can often shape the action logic of the lower-level government. When the higher-level government attaches great importance to the response work and introduces the system to regulate and supervise the response behavior of the lowerlevel government, the response level of the lower-level government will be significantly improved.

Based on the above analysis, hypotheses $\left(H 1_{P}, H 1_{S}, H 1_{Q}\right.$, and $H 1)$ are proposed. The relationship between E-GR $\left(R_{E \text {-government }}\right)$, responsiveness probability $\left(R_{P}\right)$, responsiveness speed $\left(R_{S}\right)$, responsiveness quality $\left(R_{Q}\right)$, and government response system $(S)$ can be described as follows:

$$
\begin{aligned}
H 1_{P}: R_{P} & =r_{11} f(S), \\
H 1_{S}: R_{S} & =r_{12} f(S), \\
H 1_{Q}: R_{Q} & =r_{13} f(S), \\
H 1: R_{E-\text { government }} & =R_{P}\left(R_{S}+R_{Q}\right)=r_{14} f(S),
\end{aligned}
$$

where $r_{11}, r_{12}, r_{13}$, and $r_{14}$ are positive correlation coefficients. 
TABLE 3: Examples of local government response system.

\begin{tabular}{|c|c|c|}
\hline $\begin{array}{l}\text { Government } \\
\text { level }\end{array}$ & Name of policy & $\begin{array}{l}\text { Time of } \\
\text { introduction }\end{array}$ \\
\hline \multirow{3}{*}{ Province } & $\begin{array}{c}\text { The People's Government of Anhui Province: "Further Strengthen and Standardize the Working Rules of } \\
\text { the Governor's Mailbox, Governor's Hotline and Online Message Handling" }\end{array}$ & 2014 \\
\hline & $\begin{array}{l}\text { Liaoning Provincial People's Government: "Opinions on Further Strengthening and Improving the } \\
\text { Handling of Letters from the People and Messages from the People's Website" }\end{array}$ & 2016 \\
\hline & $\begin{array}{c}\text { Hunan Provincial People's Government: "Rules for Handling Letters from 'Governor's Mailbox' on the } \\
\text { Portal Website of Hunan Provincial People's Government" }\end{array}$ & 2018 \\
\hline \multirow{3}{*}{ City } & $\begin{array}{l}\text { Huainan Municipal People's Government: "Measures for the Administration of Mayor's Mailbox on the } \\
\text { Portal Website of Huainan Municipal People's Government" }\end{array}$ & 2015 \\
\hline & $\begin{array}{c}\text { Liupanshui Municipal People's Government: "Notice on Further Strengthening the Handling of Mayor's } \\
\text { Mailbox" }\end{array}$ & 2008 \\
\hline & $\begin{array}{c}\text { Zhangjiajie Municipal People's Government: "Notice on Further Improving the Online Letter Handling } \\
\text { of 'Governor's Mailbox' and 'Mayor's Mailbox”" }\end{array}$ & 2014 \\
\hline
\end{tabular}

2.2.2. Hypothesis (H2): The Neighborhood Effect Has a Positive Impact on E-GR. In addition to the influence of local economy, technology, system, and culture, the E-GR of local government is positively correlated with the E-GR of local governments in neighboring areas. The neighboring area means that the region is geographically contiguous or adjacent and has similar institutional environment. Due to the similar culture, the governments in the neighboring areas will use symbols with cultural resonance to convey information to the public [19-22]. There are two main reasons for the positive correlation between E-GR and the neighboring areas. On the one hand, it is because the neighboring areas are similar in many aspects. Usually, these areas are affected by the same higher level of government. If the common superior government attaches great importance to the government response and formulates the corresponding assessment system, the E-GR of the lower-level government in the jurisdiction area will be improved. On the other hand, based on innovation diffusion, imitation can reduce learning cost and innovation risk. The local government will learn from the neighboring governments in the aspects of response platform construction, internal operation process, response system construction, and talent introduction and training so as to improve the E-GR. What is more, when the superior government brings the response construction into the institutional framework, the neighboring governments at the same level will enter into a fierce "competition" state. In order to win in the "game" of competing for resources, winning honors and awards, and winning promotion opportunities, the local government will be more motivated to attach importance to and strengthen E-GR. Since the introduction of grassroots democracy in China in the 1990s, in addition to "economic performance," the "public opinion in the jurisdiction" has also played a very important role in the political "game" of local officials" promotion $[23,24]$. Therefore, it is an important measure to win public opinion by attaching importance to the response to citizens' demands.

Based on the above analysis, hypotheses $\left(H 2_{P}, H 2_{S}, H 2_{Q}\right.$, and $H 2)$ are proposed. The relationship between E-GR $\left(R_{E-}\right.$ government), responsiveness probability $\left(R_{P}\right)$, responsiveness speed $\left(R_{S}\right)$, responsiveness quality $\left(R_{Q}\right)$, and the competition between governments $(C)$ can be described as follows:

$$
\begin{aligned}
H 2_{P}: R_{P} & =r_{21} f(C), \\
H 2_{S}: R_{S} & =r_{22} f(C), \\
H 2_{Q}: R_{Q} & =r_{23} f(C), \\
H 2: R_{\text {E-government }} & =R_{P}\left(R_{S}+R_{Q}\right)=r_{24} f(C),
\end{aligned}
$$

where $r_{21}, r_{22}, r_{23}$, and $r_{24}$ are positive correlation coefficients.

2.2.3. Hypothesis (H3): The citizens' Interaction Demands Have a Positive Impact on E-GR. In the process of the interaction between the government and the citizens, the citizens are not only the proposer of the response, but also the receiver of the government response. Only when there is an appeal can there be a response. The appeal ability and influence of citizens will also have a certain impact on the E-GR. In theory, any nondirectly elected local government lacks the direct impetus to respond to the public's demands. Because of the long chain of principal-agent, local governments or administrative bureaucrats as agents are often willing to be responsible for their direct clients. In the Internet age, the local governments interact with the citizens through e-government. The network interaction is a complex process, and the relationship between the government and the citizens is not close $[25,26]$. In China, the direct client of the local government is its superior government, so the threat of reporting to the superior will also make the local government more active in responding to citizens' demands [3].

However, this does not negate the impact of citizens' interaction demands on E-GR. On the one hand, from the perspective of political science, enhancing the government's response is a powerful measure to enhance the government's trust and win the popular support. Popular support is the most important thing for politics. The citizens' trust in the government is the legitimate foundation of rule [27]. Therefore, strengthening the government response will help enhance the legitimacy and credibility of the government. And a wise government should also know how to respect public opinion. On the other hand, from the perspective of economics, government response is also a rational calculation based on cost-benefit consideration. In China, maintaining stability is a task that the central government 
attaches great importance to. If local turmoil caused by collective actions of the citizens occurs, it will directly threaten the career and the political promotion of the local officials [3]. Therefore, based on the rational consideration, when the public's ability and influence are strong, in order to avoid public opinion condemnation and reduce the risk of maintaining stability, it is necessary for the local governments to actively respond to the citizens' demands. It is also found in this study that if the government manages the media information, it can effectively affect the public's intention [28]. The social interaction between the citizens will cause the demand for interaction between the citizens and the government [29]. Then, it will promote the local government to improve the E-GR. In addition, the scale of Internet users and the proportion of Internet users in a region have also become an important indicator to measure the ability of citizens to participate in and discuss politics on the Internet. It is found that the level of e-government in a country is significantly correlated with the level of e-democracy and the number of Internet users [2].

Based on the above analysis, hypothesis $(H 3)$ is proposed. The relationship between E-GR $\left(R_{E-\text { government }}\right)$ and the citizen interaction demands $(I)$ can be described as follows:

$$
\begin{aligned}
H 3_{P}: R_{P} & =r_{31} f(I), \\
H 3_{S}: R_{S} & =r_{32} f(I), \\
H 3_{Q}: R_{Q} & =r_{33} f(I), \\
H 3: R_{\text {E-governmant }} & =R_{P}\left(R_{S}+R_{Q}\right)=r_{34} f(I),
\end{aligned}
$$

where $r_{31}, r_{32}, r_{33}$, and $r_{34}$ are positive correlation coefficients.

\section{Research Design and Variable Operationalization}

3.1. Research Design. In order to obtain the objective data of E-GR, a field experiment was conducted based on 480 local government portal websites in China. The specific method is to submit two appeals to each government website as a citizen to examine its responsiveness. In order to ensure the authenticity of the interaction, the two appeals that were designed are derived from the real life. After extensive research and review of the appeals on the government websites, "Consultation on House Purchase Matters" and "City Image Suggestions" were finally determined as the appeals in the experiment.

In this experiment, the samples were collected from 31 provincial administrative units except Hong Kong, Macao, and Taiwan. Taking the list of cities from "China City Statistical Yearbook" as the sampling frame, 480 cities including 220 cities at prefecture level and 260 cities at county level were randomly selected. The survey was conducted from May to June in 2018. The specific steps were as follows: (1) the members of the research group send the two prepared appeals to leadership mailbox of 480 government websites in two rounds, and each local government could receive two appeals in succession; (2) after 30 working days, they logged on to the government websites to check the governments' response content and filled in the corresponding form; (3) they coded the response contents to reflect E-GR.

3.2. Operation of Independent Variables. According to the above theoretical hypothesis and analysis framework, there are three core explanatory variables in this study. The specific operations are as follows. (1) Regarding government response system, through the government portal website and other authoritative media, it is checked whether the local governments have formulated response policies, such as "Mayor's Mailbox Management Measures" and "Mayor's Mailbox Message Handling Regulations," which can stimulus the response behavior. If the city has formulated response policy, the variable is coded as 1 ; otherwise, it is coded as 0 . This variable is a binary variable. (2) Regarding neighborhood response level, other cities of the same level in the same province are regarded as neighboring cities and measure neighborhood response level by comparing the average response level of neighboring cities with the average response level of cities of the same level across the country. When the average response level of neighboring cities is higher than the national average level, the variable is coded as 1 ; otherwise, it is coded as 0 . This variable is also a binary variable. (3) Regarding citizen interaction demands, the "number of messages per capita" in the message board is used for local leaders of People's Daily Online to measure the interaction demands of citizens. The message board for local leaders of People's Daily Online has been widely concerned by local leaders and citizens since it was officially launched in 2008, which has become the largest, most active, and most mature network political platform in China. Since it is not interfered and controlled by local government, the authority and authenticity of its data can be guaranteed. The "number of messages per capita" is calculated by dividing the annual total number of messages by the total number of regional population. The annual total number of messages comes from the official website of People's Daily Online, and the total number of regional population comes from "China City Statistical Yearbook 2018." The variable is a continuous variable.

\section{Results and Analysis}

4.1. Measurement Results of E-GR in China. Table 4 shows the following. (1) In our field experiment, 839 appeals were submitted successfully, and 121 appeals failed due to problems such as the government website which could not be opened or registration was blocked, with a success rate of $87 \%$. (2) A total of 417 valid responses were received from the government, with a response rate of about $50 \%$ (417/839). (3) The average response speed is 25.76 , which indicates that most of the appeals have been responded quickly. (4) The average response quality is 3.81 , which is at a medium level. (5) Comparing the response levels of different levels of local governments, it is found that the response rate of prefecturelevel city governments is slightly higher than county-level cities, but the response speed and response quality scores of county-level city governments are higher than prefecturelevel cities. Figure 2 shows the distribution map of E-GR. 
TABle 4: Descriptive statistics of E-GR.

\begin{tabular}{|c|c|c|c|c|c|c|}
\hline & & Sample size & Minimum & Maximum & Mean & Sd. \\
\hline \multirow{4}{*}{ Total } & Success probability of appeal submission & 960 & 0 & 1 & 0.87 & 0.332 \\
\hline & Response probability & 839 & 0 & 1 & 0.50 & 0.500 \\
\hline & Response speed & 417 & 1 & 30 & 25.76 & 5.393 \\
\hline & Response quality & 417 & 1 & 6 & 3.81 & 1.323 \\
\hline \multirow{4}{*}{ Prefecture level } & Success probability of appeal submission & 440 & 0 & 1 & 0.84 & 0.364 \\
\hline & Response probability & 371 & 0 & 1 & 0.53 & 0.500 \\
\hline & Response speed & 196 & 1 & 30 & 25.61 & 6.000 \\
\hline & Response quality & 196 & 1 & 6 & 3.80 & 1.385 \\
\hline \multirow{4}{*}{ County level } & Success probability of appeal submission & 520 & 0 & 1 & 0.90 & 0.300 \\
\hline & Response probability & 468 & 0 & 1 & 0.47 & 0.500 \\
\hline & Response speed & 221 & 6 & 30 & 25.90 & 4.800 \\
\hline & Response quality & 221 & 1 & 6 & 3.82 & 1.269 \\
\hline
\end{tabular}

\subsection{Regional Differences of E-GR in China}

4.2.1. Provincial Distribution of E-GR. As shown in Figure 3, 31 provinces in China can be divided into three levels according to the response rate. (1) The first group is the three provinces with response rate of above $80 \%$, of which Ningxia ranked first (90\%), Hainan ranked second (89\%), and Zhejiang ranked third (83\%). (2) The response rate of the second group ranged from $40 \%$ to $80 \%$; Fujian (80\%), Qinghai (67\%), Henan (65\%), Hubei (61\%), and Guizhou (56\%) and other provinces are in this range. (3) The response rate of the third group is less than $40 \%$, specifically including Liaoning (30\%), Jilin (25\%), Gansu (22\%), Heilongjiang $(21 \%)$, and Xinjiang (13\%). At first glance, the response rate of local governments in China shows a certain north-south difference, and the southern region is higher than the northern region.

The provinces can also be roughly divided into three levels according to the response speed. (1) The first group includes provinces such as Beijing, Tibet, Shanghai, and Zhejiang, with a response speed of more than 28 points. (2) The second group includes provinces such as Heilongjiang, Liaoning, Fujian, Shanxi, Hainan, and Hebei, with a response speed between 25 and 28 points. (3) The third group includes provinces such as Shanxi, Guangxi, Qinghai, Guangdong, and Inner Mongolia, with a response speed below 25 points. From a preliminary point of view, the response speed of the local governments in China shows a certain north-south difference, and response speed of the southernmost and northernmost regions is lower than that of the central region. At the same time, there is also a certain east-west difference, and the response speed of eastern region is higher than that of the western region.

The provinces can also be roughly divided into three levels according to response quality. (1) The first group scored more than 4 points, including Xinjiang, Shanghai, Liaoning, Shanxi, Sichuan, and Hubei provinces. (2) The second group scored between 3.5 and 4, including provinces such as Zhejiang, Fujian, Anhui, Guizhou, Heilongjiang, Jilin, and Hainan. (3) The third group scored below 3.5, including provinces such as Gansu, Shanxi, Henan, Tibet, and Hebei. From a preliminary point of view,

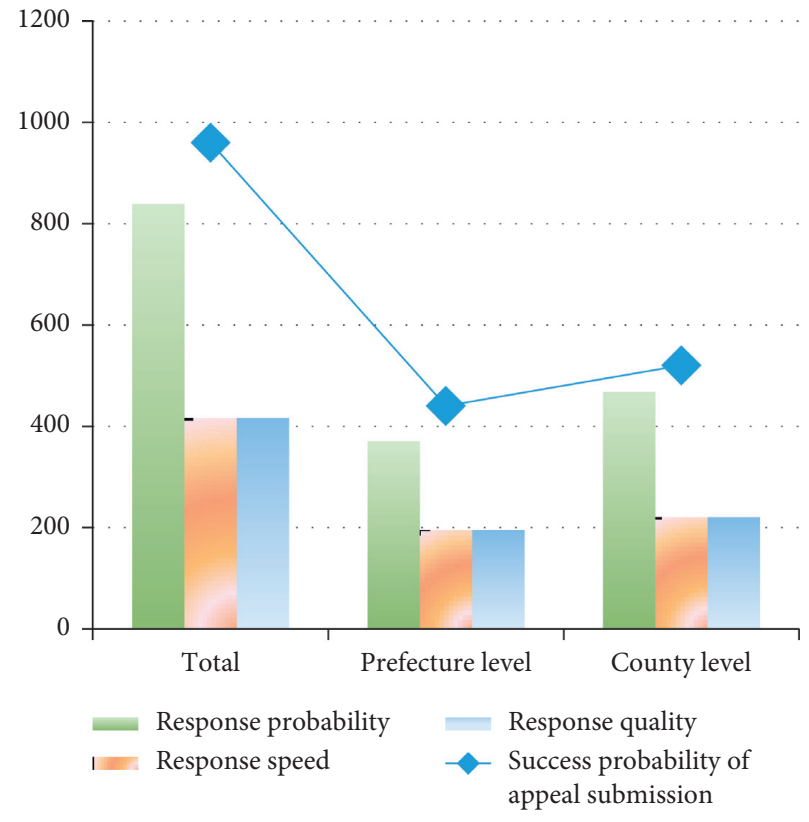

Figure 2: Distribution map of E-GR.

the response quality of the local governments in China also shows certain regional characteristics. The score of response quality of eastern region and northeast region is relatively concentrated, while that of the western region is quite different.

4.2.2. Regional Differences of E-GR. In this study, 31 provinces in China are divided into four regions: eastern, central, western, and northeast. The results of ANOVA analysis show that there are significant differences in e-government response probability $(P<0.001)$ and e-government response speed $(P<0.05)$ between different regions, but there is no significant difference in e-government response quality $(P>0.05)$ as shown in Table 5 .

Post Hoc Multiple Comparisons (Scheffe) results show that: (1) The response probability of local government in the northeastern region is the lowest, significantly lower than 


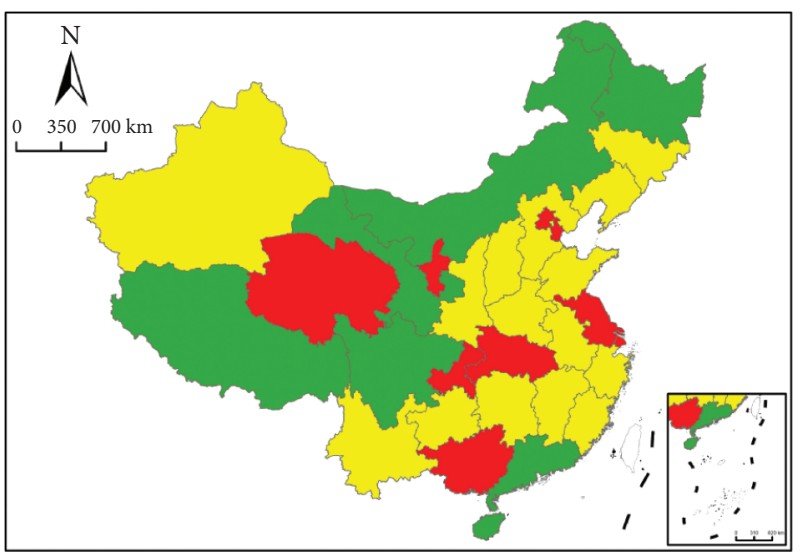

$0.96-1.00$

$\square$ 0.86-0.95
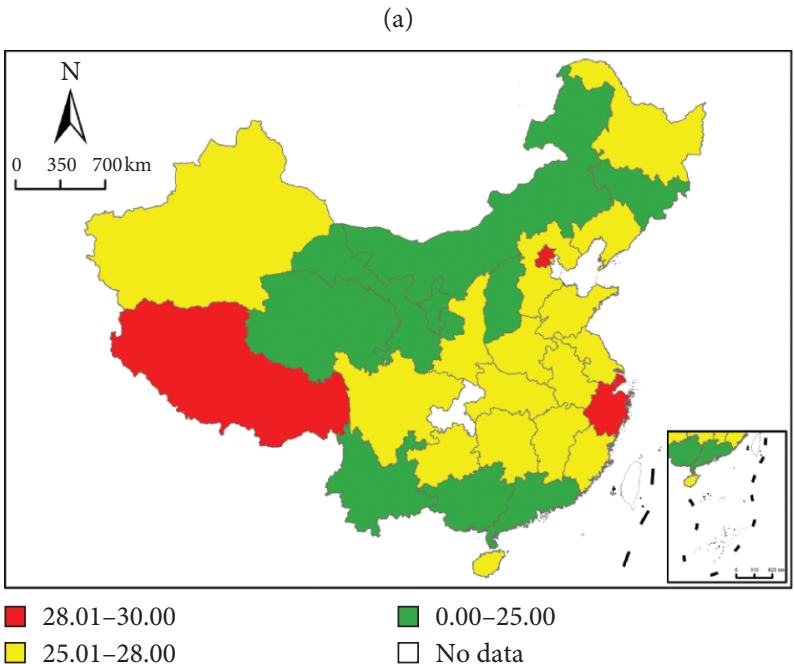

(c)

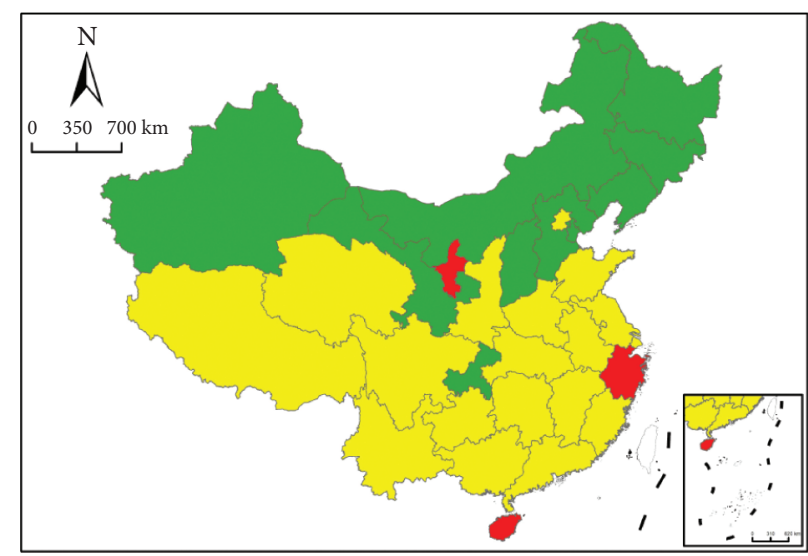

$0.81-0.90$

0.41-0.80

$\square$ No data

(b)

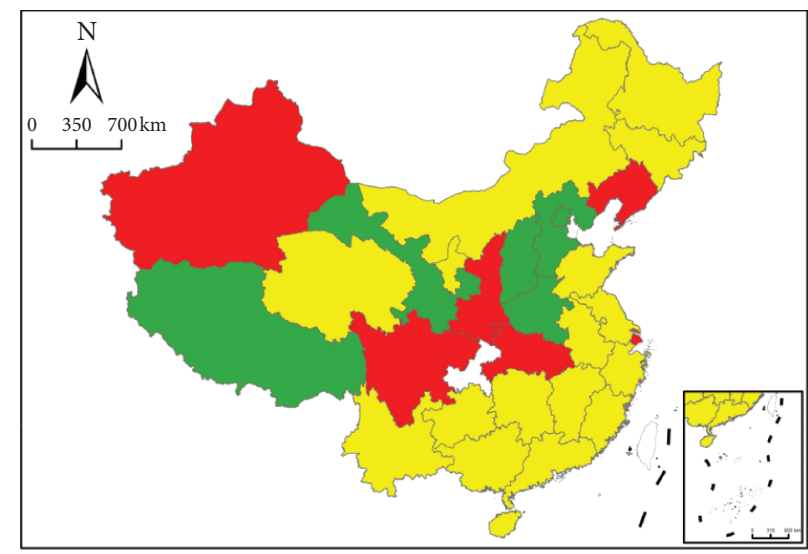

4.01-5.20

$3.51-4.00$ $\square 0.00-3.50$

$\square$ No data

Figure 3: Provincial distributions of government response levels. (a) Success probability of appeal submission. (b) Response probability. (c) Response speed. (d) Response quality.

TABle 5: Regional differences of E-GR in China.

\begin{tabular}{lccccc}
\hline & & Sum of squares & $\mathrm{d} f$ & Mean square & $F$ \\
\hline \multirow{2}{*}{ Response probability } & Between groups & 8.487 & 3 & 2.829 & \multirow{2}{*}{11.74} \\
& Within groups & 201.255 & 835 & 0.241 & \multirow{2}{*}{$0.000^{* * *}$} \\
\hline \multirow{2}{*}{ Response speed } & Between groups & 296.304 & 3 & 98.768 & \multirow{2}{*}{3.46} \\
& Within groups & 11801.715 & 413 & 28.576 & $0.017^{*}$ \\
\hline \multirow{2}{*}{ Response quality } & Between groups & 5.045 & 3 & 1.682 & \multirow{2}{*}{0.96} \\
& Within groups & 722.988 & 413 & 0.411 \\
\hline
\end{tabular}

${ }^{*} p<0.05,{ }^{* *} P<0.01$, and ${ }^{* * *} P<0.001$.

western, central, and eastern regions, and the response probability of local government in western region is significantly lower than the eastern region. (2) In terms of response speed, there are significant differences between western region and eastern region, and the response speed of local government in eastern region is significantly higher than that of the western region. (3) In terms of response quality, there is no significant differences between the four regions.
4.3. Analysis of Influencing Factors of E-GR in China. This study uses regression analysis to test the research hypothesis to explore the factors that influence the level of government response. The dependent variable contains three indicators: response probability, response speed, and response quality. "Response probability" is a binary variable, so the binary logistic model is used for analysis. "Response speed" and "response quality" are continuous variables, so linear regression model is used for analysis, as shown in Table 6. 
TABLE 6: Regression analysis of influencing factors of E-GR in China.

\begin{tabular}{lccc}
\hline & $R_{P}$ & $R_{S}$ & $R_{Q}$ \\
\hline$S$ & $8.055^{* * *}$ & $3.107^{* * *}$ & -0.069 \\
$C_{P}$ & $3.027^{* * *}$ & & \\
$C_{S}$ & & $2.888^{* * *}$ & $0.752^{* * *}$ \\
$C_{Q}$ & & $0.13 .111^{*}$ \\
$C$ & & & $0.524^{* * *}$ \\
$I$ & 1.001 & -0.005 & 0.083 \\
\hline${ }^{*} p<0.05,{ }^{* *} P<0.01$, and ${ }^{* * *} P<0.001 . C_{P}$ : neighborhood response probability, $C_{S}:$ neighborhood response speed, and $C_{Q}:$ neighborhood response quality.
\end{tabular}

According to the results of regression analysis, the regression equation is as follows:

$$
\begin{aligned}
g\left(\widehat{R}_{P}\right) & =\operatorname{Logit}\left(\frac{R_{P}}{1-R_{P}}\right)=-1.775+2.086^{*} S+1.108^{*} C_{P}+0.001^{*} I, \\
\widehat{R}_{S} & =21.411+3.107^{*} S+2.888^{*} C_{S}-0.005^{*} I, \\
\widehat{R}_{Q} & =3.467-0.069^{*} S+0.752^{*} C_{Q}+0.008^{*} I, \\
\widehat{R}_{E-\text { government }} & =6.134+13.111^{*} S+8.524^{*} C+0.083^{*} I .
\end{aligned}
$$

Regression analysis shows that China's e-government responsiveness is influenced by multiple factors. Among them, the government response system and neighborhood response level in the SCI analysis model have a significant impact on the e-government response level, but the impact of the interaction demands of citizen on the response level of e-government has not been verified. The reasons behind it deserve further analysis and discussion.

First of all, the government response system has a significant impact on the response probability and response speed, but it has no significant impact on the response quality. On the one hand, this result verifies the previous research hypothesis that "superior government authority" and "rigid response system" can drive the government to improve the response level. When local governments, especially their direct superior governments, attach great importance to online appeals of citizens, when a rigid, standardized system is introduced to constrain the government's response, and when the response level and mass satisfaction are used as the criteria for government performance evaluation, the government's response rate and response speed will be significantly improved. On the other hand, the conclusion that the government response system has no significant impact on response quality indicates that the response system is not omnipotent, because the current response system does not include response quality in the assessment mechanism or because the judgment standard of response quality is relatively vague, and it is difficult to evaluate. The local governments are prone to "procedural response," "bureaucratic response," and "perfunctory response," which are more subtle and difficult to eradicate response quality problems in their responses.
Secondly, the response level of neighborhood has a significant impact on response probability, response speed, and response quality. This result strongly verifies the research hypothesis proposed above based on innovation diffusion theory and political championship theory, indicating that intergovernmental learning and competition are indeed conducive to the improvement of local government responsiveness.

Finally, the interaction demands of citizen have no significant impact on response probability, response speed, and response quality. This result is contrary to the previous research hypotheses based on political legitimacy theory and rational economic man theory. The emergence of the results might be the reason of the following three aspects. First, there is a deviation in the measurement of the variable "the interaction demands of citizen." Due to the differences in the construction and operation of various local political discussion platforms and political-civilian interactive platforms, citizens in some areas can meet their own demands by using their own local platforms. The "annual average number of messages per person" in the message board of People's Daily Online may not accurately reflect citizens' interactive demands. Second, the strength of citizens' opinions can usually affect the government's response to emergencies, but it does not have a significant impact on normalized responses. Normalized responses rely more on normalized mechanism constraints. Third, although in theory the power of the government comes from the people, there is the need to respond to public opinion to enhance its political legitimacy. However, in the actual operation process, it is the higher-level government rather than the people of the jurisdiction that directly control the development 
resources and promotion of the local government. Therefore, the local government responds to the incentives and constraints more from the higher-level government rather than the people of the jurisdiction, which leads to the interactive demands of the citizens not being able to affect the response level of local governments.

\section{Conclusion and Enlightenment}

5.1. Research Conclusion. This paper constructs a SCI analysis model of the influencing factors of e-government responsiveness in China and then uses 960 online evaluation data of local government portals to conduct an empirical test and finally draws the following conclusions. (1) The government response system has a significant positive impact on the response probability and response speed, but the impact on the response quality is not significant. (2) The neighborhood response level has a significant impact on the response probability, response speed, and response quality, which shows that there is an obvious peer effect in local government's responses. (3) The interaction demands of citizen have no significant impact on response probability, response speed, and response quality.

5.2. Practical Implications. The research conclusions of this paper have some practical implications for improving the level of government response. (1) The interprovincial distribution of government response levels shows that the response rate, response speed, and response quality of provinces such as Zhejiang and Fujian have performed well and that the subsequent research can be refined into a typical model, summarizing the regional development model, such as "Zhejiang Model" or "Fujian Model," so as to make theoretical preparations for the promotion of its successful experience. (2) The construction of the response system has an important impact on improving the level of government response. In the future, the driving role of the system should be brought into full play. The system of government response should be established and improved from top to bottom, and the responsible subject and standardized process of response should be clarified. The response rate, response speed, and response quality are incorporated into the government's performance appraisal system. In particular, the appraisal of response quality should not be a mere formality. The degree of problem-solving and the satisfaction of the people should be taken as important criteria for quality appraisal. (3) The level of neighborhood response has a significant positive impact on government response. In the future, the driving role of intergovernmental competition and neighborhood effects should be brought into full play. Especially for provincial governments, the external community should consciously build a regional community for government response construction and, at the same time, compete and cooperate with neighboring provinces in government response; internally, it is necessary to regularly assess and publish the level of government response at all levels of the city, give certain rewards to the lower-level governments that rank high, and criticize the lower-level governments that rank the bottom. The government's response level and the public opinion of the jurisdiction are taken as important criteria for the promotion and assessment of lower-level officials, and a healthy atmosphere of competition is gradually created within the province. (4) In essence, government response is an interactive behavior between the government and the citizens. The demands of citizens are the original intention of the government's response. Therefore, the citizens' influence should be the core driving force of the government's response. In the future, it is necessary to shift from "system-driven response" and "competition-driven response" to "citizen-driven response." Only in this way can people truly focus on the people and increase the public satisfaction of government responses.

\section{Data Availability}

City and population data are derived from "China City Yearbook 2018", which are open and available. https://navi.cnki.net/ KNavi/YearbookDetail?pcode=CYFD\&pykm=YZGCA\&bh=.

\section{Conflicts of Interest}

The authors declare that they have no conflicts of interest.

\section{Authors' Contributions}

Shaoqing Tian was responsible for proposing the overall idea and framework of the manuscript. Rongrong He was responsible for data collection, processing, and writing of the first draft of the manuscript. Chongli Huang was responsible for the revision of the manuscript. Qiong Feng and Fan Jiang were responsible for proofreading and translation. Shaoqing Tian, Rongrong He, and Chongli Huang contributed equally to this paper and are regarded as the first authors.

\section{Acknowledgments}

This work was supported by Humanities and Social Sciences Research Innovation Team of Hainan University, Hainan Free Trade Port Cross-border E-commerce Service Innovation Research Team (HDSKTD202025). This work was also supported by Hainan Provincial Natural Science Foundation of China (720RC567, Research on Information Compensation Mechanism of Free Trade Zone to Global Supply Chain Innovation Coordination under Block Chain Technology, and 720RC569, Tourism Value Chain Distribution and Ecological Optimization Mechanism of Hainan International Tourism Consumption Center Based on System Dynamics).

\section{References}

[1] V. Viswanath, F. K. Y. Chan, and J. Y. L. Thong, "Designing e-government services: key service attributes and citizens' preference structures," Journal of Operations Management, vol. 30, no. 1-2, pp. 116-133, 2012.

[2] C.-p. Lee, K. Chang, and F. S. Berry, "Testing the development and diffusion of e-government and e-democracy: a global perspective," Public Administration Review, vol. 71, no. 3, pp. 444-454, 2011. 
[3] J. Chen, J. Pan, and Y. Xu, "Sources of authoritarian responsiveness: a field experiment in China," American Journal of Political Science, vol. 60, no. 2, pp. 383-400, 2015.

[4] J. H. Kuklinski and J. E. Stanga, "Political participation and government responsiveness: the behavior of California superior courts," American Political Science Review, vol. 73, no. 4, pp. 1090-1099, 1979.

[5] Z. Su and T. Meng, "Selective responsiveness: online public demands and government responsiveness in authoritarian China," Social Science Research, vol. 59, pp. 52-67, 2016.

[6] S. Grohs, C. Adam, and C. Knill, "Are some citizens more equal than others? Evidence from a field experiment," Public Administration Review, vol. 76, no. 1, pp. 155-164, 2016.

[7] A. Savoldelli, C. Codagnone, and G. Misuraca, "Understanding the e-government paradox: learning from literature and practice on barriers to adoption," Government Information Quarterly, vol. 31, pp. 63-71, 2014.

[8] J. P. Olsen, "Democratic order, autonomy, and accountability," Governance, vol. 28, no. 4, pp. 425-440, 2015.

[9] D. P. Moynihan, "Managing for results in state government: evaluating a decade of reform," Public Administration Review, vol. 66, no. 1, pp. 77-89, 2006.

[10] J. Hassid and J. N. Brass, "Scandals, media and good governance in China and Kenya," Journal of Asian and African Studies, vol. 50, no. 3, pp. 325-342, 2015.

[11] J. K. Kamara, B. W. Sahle, K. E. Agho, and A. M. N. Renzaho, 'Governments' policy response to drought in Eswatini and Lesotho: a systematic review of the characteristics, comprehensiveness, and quality of existing policies to improve community resilience to drought hazards," Discrete Dynamics in Nature and Society, vol. 2020, Article ID 3294614, 17 pages, 2020.

[12] T. Xu and J. Ma, "Feed-in tariff or tax-rebate regulation? Dynamic decision model for the solar photovoltaic supply chain," Applied Mathematical Modelling, vol. 89, pp. 11061123, 2021.

[13] J. H. Ma, Y. M. Hou, Z. X. Wang, and W. H. Yang, "Pricing strategy and coordination of automobile manufacturers based on government intervention and carbon emission reduction," Energy Policy, vol. 148, pp. 1-15, 2021.

[14] X. Q. Zhang, X. G. Yuan, and D. L. Zhang, "Research on closed-loop supply chain with competing retailers under government reward-penalty mechanism and asymmetric information," Discrete Dynamics in Nature and Society, vol. 2020, Article ID 7587453, 20 pages, 2020.

[15] Q. Gao and J. H. Ma, "Chaos and Hopf bifurcation of a finance system," Nonlinear Dynamics, vol. 58, no. 1-2, pp. 209-216, 2009.

[16] C. C. Maxime, L. Ruben, and P. Georgia, "The impact of demand uncertainty on consumer subsidies for green technology adoption," Management Science, vol. 62, pp. 1235$1258,2015$.

[17] J. Ma and H. Ren, "Influence of government regulation on the stability of dual-channel recycling model based on customer expectation," Nonlinear Dynamics, vol. 94, no. 3, pp. 1775-1790, 2018.

[18] L. Wilson and E. Elina, "Institutional legitimacy and Russian news: case studies of four regional newspapers," Political Communication, vol. 27, no. 3, pp. 275-288, 2010.

[19] D. Levin, "Framing peace policies: the competition for resonant themes," Political Communication, vol. 22, no. 1, pp. 83-108, 2005.

[20] J. Ma and L. Xie, "The comparison and complex analysis on dual-channel supply chain under different channel power structures and uncertain demand," Nonlinear Dynamics, vol. 83, no. 3, pp. 1379-1393, 2016.

[21] J. H. Ma and L. Sun, "Complexity analysis about nonlinear mixed oligopolies game based on production cooperation," IEEE Transactions on Control Systems Technology, vol. 26, no. 4, pp. 1-8, 2018.

[22] E. Thomann, N. van Engen, T. Lars, and L. Tummers, "The necessity of discretion: a behavioral evaluation of bottom-up implementation theory," Journal of Public Administration Research and Theory, vol. 28, no. 4, pp. 583-601, 2018.

[23] T. G. Meng and J. Zhao, "Responsive government driven by network: institutional diffusion and operation mode of network politics," The Journal of Shanghai Administration Institute, vol. 19, no. 3, pp. 36-44, 2018.

[24] J. X. Liu, "A study on the competition of China's political Championships," Journal of Public Management, vol. 5, no. 3, pp. 24-122, 2008.

[25] E. W. Welch and S. Fulla, "Virtual interactivity between government and citizens: the chicago police department's citizen ICAM application demonstration case," Political Communication, vol. 22, no. 2, pp. 215-236, 2005.

[26] C. Pollitt, "Performance management in practice: a comparative study of executive agencies," Journal of Public Administration Research and Theory, vol. 16, no. 1, pp. 25-44, 2006.

[27] K. Elad and R. Joshua, "Like, Post, and Distrust? How social media use affects trust in government," Political Communication, vol. 37, no. 1, pp. 46-64, 2020.

[28] G. Avi and E. T. Catherine, "Privacy regulation and online advertising," Management Science, vol. 57, no. 1, pp. 57-71, 2010.

[29] J. H. Ma, Z. B. Guo, and Y. L. Hong, "Demand-supply dynamics in FMCG business: Exploration of customers' herd behavior," Nonlinear Dynamics, vol. 98, pp. 1669-1681, 2019. 